ISSN: 2653-8822

\title{
Research and Human Rights - Surrogacy and Interference in Human Genome
}

\author{
Kalomoira K. Sakellaraki \\ PhD Candidate in Applied Ethics Philosophy \\ National and Kapodistrian University of Athens \\ and University of Peloponnese \\ email: kalsakellaraki@gmail.com
}

\begin{abstract}
:
The development of biotechnology and life sciences has led to a clash between the endeavor for research and human dignity. Issues have been raised about biotechnological practices, not only for treatment but also for research. Genetic technology refers to the methods that make enable the interference in the structure of the genes that are found in the cell nucleus. The body of all this information is the individual's genome. By mapping the genome, it is now possible to diagnose hereditary diseases and abnormalities that humans might develop after their birth and during their lifetime. Such techniques and investigations lead not only to negative eugenics by the fetus' exclusion due to an abnormality, but to a positive one as well because perfect humans are chosen for implantation. Law, therefore, faces life as damage. Such cases have led to the enactment of a law which stipulates that life deserves/is worth per se, and the recognition of the individual's right not to be born with the value of individual is incompatible. On the contrary, it is argued that neither can the individual submit to a transcendent value of the human genus nor can the individual right to resort to Justice for a health problem that makes life difficult be annulled. Nevertheless, it appears that such a process leads to the hetero-definition of the human species and inevitably to the abasement of human dignity, since the principle of dissimilarity is abolished, and healthy patterns are created. Typical is the case of Recommendation 932 of the Council of Europe, which states that as a person has the right to life and human dignity, so one has the right to unchangeable hereditary features.
\end{abstract}

Keywords: Human dignity, research, genome, hereditary diseases, eugenics

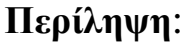

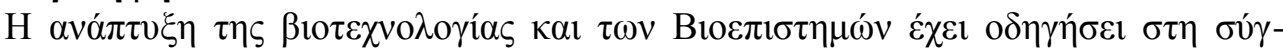

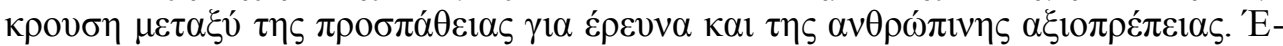

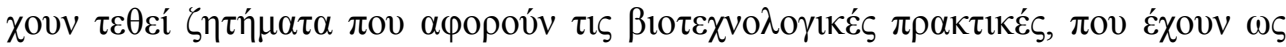

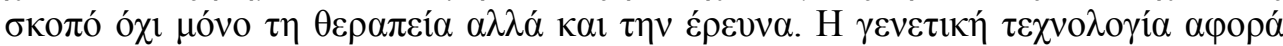

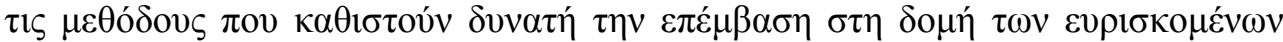

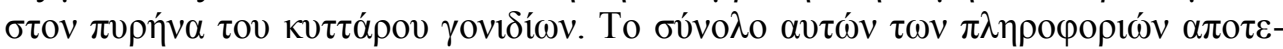




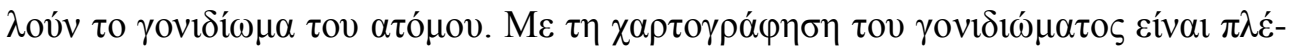

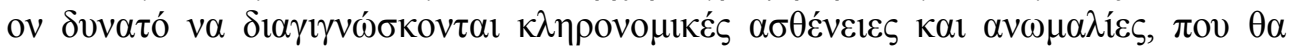

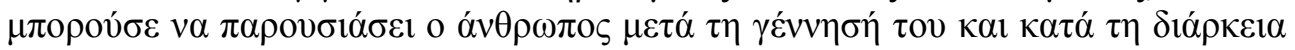

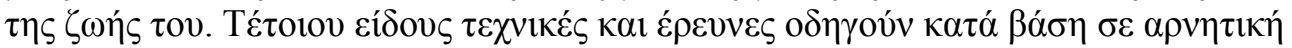

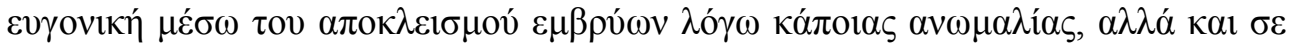

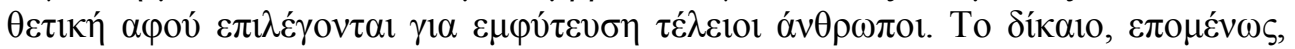

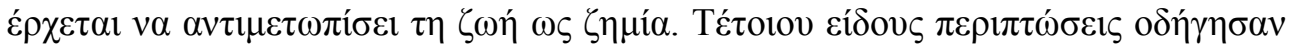

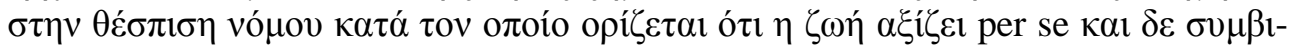

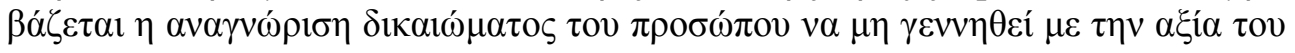

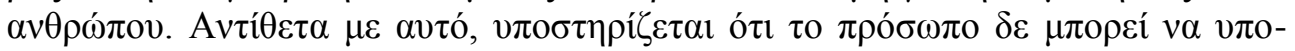

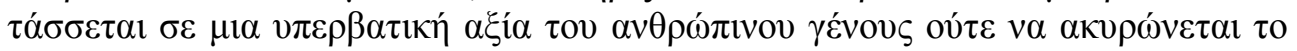
$\alpha \tau$ о

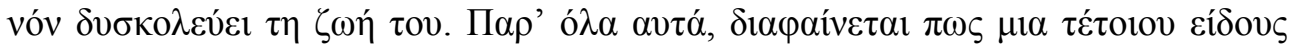

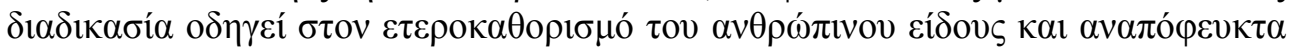

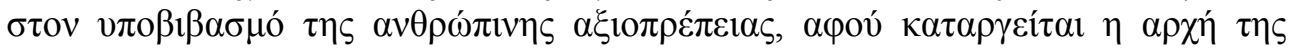

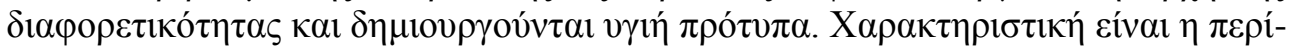

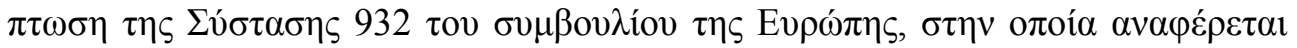

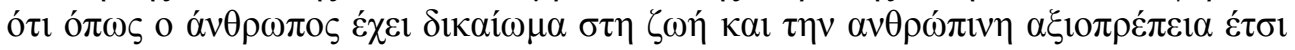

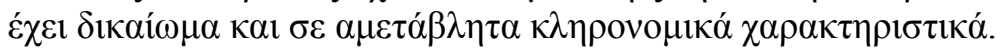

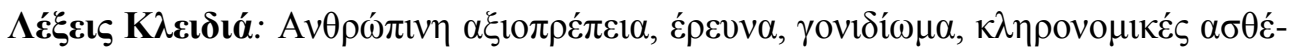

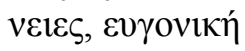

\section{Research and Human Rights}

\section{- Surrogacy and Interference in Human Genome}

The development of Biotechnology and Life sciences has led to a confrontation between the effort for research and human dignity. According to Article 16 (1) of the Convention the protection of freedom is unconditional. However, it seems that it cannot exist contrary to human dignity. This is also reflected on Article 25 (3) of the Convention, in which the abuse of rights is prohibited. Nevertheless, issues have been raised about biotechnological practices, which are aimed not only at treatment but also at research. Genetic technology refers to methods that make possible the interference in the gene's structure found in the cell's nucleus. The body of all this information is the individual's genome (Kriari-Katrani, 1994). During in vitro fertilization - procedures, either on the natural mother, or on the surrogate, more than one egg is fertilized, to avoid any inconvenience and health problems that could be caused by the excessive genetic material intake. It is observed that doctors take the initiative to choose the finest eggs from the surplus fertilized for implantation through pre-implantation control. By mapping the genome, it is now possible to diagnose hereditary diseases and abnormalities that humans might develop after their birth and during their lifetime (Kriari-Katrani, 1994).

Such techniques and investigations lead not only to some negative eugenics by the fetus' exclusion due to an abnormality, but also to positive ones because perfect 
humans are chosen for implantation. Law, therefore, faces life as damage. The individual ought to create ideal patterns in a world where diversity will disappear, while children will become objects that will serve different parenting needs. This is an early stage process and aims to protect parents from giving birth to "defective" children. Nevertheless, this attitude transforms the child into a means of personal, selfish needs and it is treated as an unworthy life. It is worth noting that doctors bear civil liability if the child is born with a genetic disorder (Papachristou, 2007, p18). Such cases have led to the enactment of a law ${ }^{1}$ that states that life is worth per se and the recognition of the individual's right not to be born with the value of individual is incompatible. On the other hand, it is argued that neither the individual may submit to a transcendent value of the human genus, nor can the individual's right to resort to Justice for a health problem that makes his life difficult be annulled. Nevertheless, it appears that such a process leads to the hetero-definition of the human species and inevitably to the abasement of human dignity, since the principle of dissimilarity is abolished, and healthy patterns are created.

Another purpose that such methods can serve is to select a donor with histocompatibility in cases where the child needs a graft to treat the disease. Therefore, through artificial fertilization, the birth of the new child will save the life of its sibling. In such cases, more ova are fertilized and one that has identical genetic material to the child's sibling is selected to be born (Simeonidou-Kastanidou, 2002, p.1053). In such a case, the child saves the sibling's life. However, there are objections because there is no real will on the part of the parents to give birth to a child, while it is used to save another life without being treated as an integrated person, but it exists because of another person's life. On the other hand, more importance is attached to the result because the child saves another person and this act cannot dispense the gift of life that is given to them and their human dignity is not affected. Even so, what could cause problems would be the creation of surplus embryos, which weren't helpful or were donated, and legally are considered non-existent. This is also the reason why embryos can be used for research either to treat the fetus or the advancement of medical science. The law that governs these biotechnological developments is the Council of Europe Convention on Human Rights and Biomedicine, which sets out the inconsistency of the parties to determine the starting point of human life and the protection of human dignity. The Convention accepts the research in embryos on condition that their protection is ensured and prohibits the creation of embryos for research purposes. However, we should clarify whether surplus embryos are considered to be inferior because their creation is prohibited for research purposes. We ought to mention that an attempt has been made to recognize human value in the embryos even though they are potential human beings ${ }^{2}$. Embryo research is permitted in many European countries for the

\footnotetext{
${ }^{1}$ L. $2002-303$ article. 11

${ }^{2}$ It is noteworthy that Professor of Genetics, Jerom Lejeune, who found out the chromosomal origin of DOWN syndrome, has stated that the study of genetic diseases does not
} 
first 14 days after fertilization. This, however, does not remove any moral and legal concerns that could arise. An embryo, even if it is created for research purposes, continues to be used as a means of achieving goals that are foreign to it and the respect for its human value. The legislator, by analyzing Article 18 (1) of the Convention, stipulates that embryo research is conducted with the term of "adequate protection" but it does not protect human dignity, because it has already been affected since it has been submitted to programs for research and experimentation. Protection here is interpreted as an insurance that embryos are kept in such a condition that these can be used for reproductive purposes at some point (Vidalis, 2003). Genetic research is considered as a basic research because its aim is to enrich the knowledge of human's biological constitution. However, if these results are applied for treatment, then it is applied research. Genetic material should only be used for childbearing. Any other use is disputed, even if it is for therapeutic purposes (e.g. stem cells) or the evolution of science. It is about human dignity, which cannot subsist on human life or health. It is worth noting at this point that the Convention stipulates applied research to treat fetus protection, even if the fertilized egg is not recognized as a living being and a carrier of human dignity. We understand that a doctor's or researcher's obligations do not diminish before the embryo treatment, otherwise, we would have an impairment in free reproduction and family creation of the individual who is interested in protecting the health of the fetus (Vidalis, 2003).

The interference in the human genome for diagnostic and therapeutic purposes is permitted by Article $\mathbf{1 3}$ of the Convention, on condition that it is not intended to modify the descendant's genome. If, indeed, this surgery is successful, then many patients will be relieved. However, these methods are at an early stage, and there is certainly the risk of transforming the genome with consequences on humans. Moreover, we ought to know that such experiments can cause irreparable damage to the fetus. On the other hand, the invasion of genetic identity is unacceptable as it is an essential element of human dignity. Typical is the case of Recommendation 932 of the Council of Europe, which states that as a person has the right to life and human dignity, so has he the right to unchangeable hereditary features (KriariKatrani, 1994). It is about a serious matter for which it is necessary to punish both the deceit to modify the human genome and the doctor's negligence, which affects the fetus' dignity and health. Human interests prevail not only over the commonweal, but also science. Nevertheless, the independent protection of human dignity is disputed by Criminal Law. Human dignity is recognized as an autonomous and universal value, which means that the acquiescence of any individual to his dignity does not entail the non-existence of such infestation of dignity as it is an individual's legitimate good. We, therefore, conclude that the process of establi-

\footnotetext{
require experimentation on embryos from which is not expected help. This experiment aims at improving the technique of in vitro fertilization, testing new drugs and exercising eugenics.
} 
shing legal goods provides relative protection, while human dignity is the one that leads to its absolute respect even if compared to the legitimate good of life (Konstantinidis, 1987). Thus, human dignity is not a legal good in the technical sense of the term in Criminal Law, and its independent criminal protection is not allowed (Manoledakis, 1995). The Constitution does not treat human value as a fundamental right but as a basic principle that governs the Law (Konstantinidis, 1987). Nevertheless, German theory argues that since the Constitution protects human value, the legislator is obliged to intervene.

The problem in the case of assisted reproduction by a surrogate mother is the excessive commitment of her free will. In fact, this is justified because the social mother is constantly worried about her pregnancy either for her development or her fetus' health. However, if the commitment of the mother's freedom is excessive, then there is a question of nullity of the agreement and the court does not grant it. The surrogate mother may have an artificial pregnancy interruption, especially during the first trimester of pregnancy if her life, or her health, are at risk. However, if the grounds that they revoke are not be proved to be serious, then there is a question of liability on the part of the carrier ${ }^{3}$. According to the law, an unmarried or unaccompanied man cannot act upon artificial reproduction procedures, because this process exists due to pathological conditions, and the male's inability to be pregnant is due to the nature of his sex. In the case of surrogate mothers, the freedom in reproduction is limited. By the agreements between the pregnant mother and the social mother, it is assigned to the surrogate mother to fertilize the fetus and to give it to the woman who is interested in the child by either fertilizing her own egg or by giving birth to an already fertilized egg. However, the following legal and ethical issues emerge in specific cases: The first concerns whether the forceful of the gradual development of the fetus and its transformation into a human being justifies the imposition of conditions for its protection which are imposed on the lifestyle of the surrogate mother during the pregnancy and affect the core of self-determination (Vidalis, 2003 and Papachristou, 2003). The second concerns the right of the mother to artificial -pregnancy interruption. It is difficult to answer these questions, as these are issues that are encountered in cases of application of the trilateral action of constitutional rights. The example of surrogate mothers concerns us even more because these are private agreements with quite significant implications for fundamental rights, such as personality development, free movement and freedom of labor. We ought to consider that the surrogate mother chooses with her own free will an agreement with particularly important

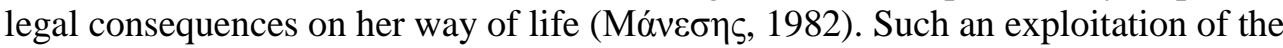
surrogate mother, with the imposition of restrictive conditions, stems from importunate needs either economic or emotional (the carrier has in some way a relationship with the "social" mother to whom she will give the child), which leads her to accept the shrinkage of her private autonomy. Therefore, something like this

${ }^{3}$ Article 335 C.L. 
proves that the agreement is not usually accepted with the free will of the surrogate mother, but it is easy to see when the terms of such an agreement lead to exploittation (Werheimer, 1992, p.212). It is worth noting that the private agreements of the mothers with the couple are concluded before the start of pregnancy and that is why the conditions that can be included are only those who are limited to a minimum of precautions. These precautions are recommended by medical science as a sine qua non condition for the smooth development of the fetus. Otherwise, should complications during the pregnancy be predicted medically, stricter conditions are guaranteed. However, any interference and personal or subjective estimation of the social, "ordering" mother should be considered immaterial even if she imposed herself on corresponding strict limitations in case she was pregnant. Such an action would impose the personal perceptions of the "ordering individual" on the mother and at the same time her special personality would be sidelined and would be turned into an object of exploitation, by prejudicing her human value and violating the ordinance 2 (1) of the Constitution.

On the other hand, the second question that it is necessary to be answered is whether the surrogate mother can still maintain her right to artificial pregnancy interruption. It is noteworthy that this woman's right is closely related to the part of self-definition, because if she is denied the opportunity to exert it, she loses the control of her biological functions, she turns into a "means" for the pursuit of a goal and we treat her in an incompatible way with the human value. Something like this gives her the free will not to waive the right to an artificially interrupted pregnancy regardless of the private agreement providences.

However, we ought to keep in mind that the Greek legislator sought to make any adjustments to the method of the loaned uterus and to regard it as a permitted method with the basic aim of the child's commonweal to be born. Moreover, it is remarkable that children can be born and in breach of it by the method of surrogacy either it is legally accepted or not. It is worth noting that the whole issue of surrogate motherhood is positively regarded, and the acceptance of this method is preferable in countries such as England, the Netherlands, Israel, Hungary and some States of the United States. Surrogacy is accepted under strict conditions, which will abrogate immorality, by regulating the issue of establishing the kinship with the woman who desires the child (article 1464 Civil Code - the principle of socioemotional kinship).

In conclution, genetic research is considered as a basic research because its aim is to enrich the knowledge of human's biological constitution. Genetic material should be used for childbearing and any other use is disputed. It is about human dignity, which cannot subsist on human life or health. Human dignity is recognized as an autonomous and universal value and not a legal good in the technical sense of the term in Criminal Law.

\section{References}


Konstantinidis, K. (1987) Criminal Law and human dignity, Athens: Ant. N. Sakkoulas (greek)

Kriari-Katrani, I. (1994) Biomedical development and Constitutional Law Athens Sakkoulas (greek)

Manesis, Ar. (1982) “Constitutional rights, a' Individual freedoms”, University teachings, Thessaloniki: Sakkoulas (greek)

Manoledakis, I. (1995) The criminal protection of human dignity, Thessaloniki:

Sakkoulas (greek)

Papachristou, Th. (2003) In vitro Fertilization in Civil Law - Law and Society in $21^{\text {st }}$ century, Athens-Thessaloniki: Sakkoulas (greek)

Papachristou, Th. (2007) "Life as damage", Vima Ideon (greek)

Simeonidou-Kastanidou, El. (2002) "Genetic technology and Civil Law”, in Poiniki Dikaiosini (greek)

Vidalis, T. (2003) Life without face - The Constitution and thw usage of the human genetic material, Athens: Sakkoulas (greek)

Wertheimer, Al. (1992) “Two Questions About Surrogacy and Exploitation”, Philosophy and PubIic Affairs, 21

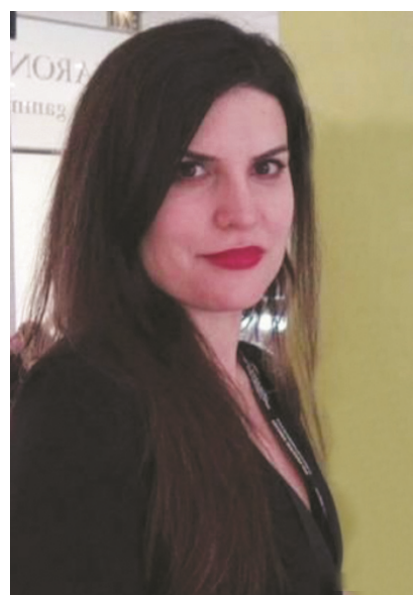

Kalomoira K. Sakellaraki has a Bachelor's Degree in Greek Philology and a Master's Certificate in Philosophy of Ethics. She is a PhD Candidate of Applied Ethics Philosophy and has completed her Doctoral Thesis, which is entitled "Surrogacy and Human Rights". The aim of her research is to clarify the aspects that surrogacy arises under the guise of various rights theories and to emphasize the essential contribution of science to the efforts of childless couples to procreate. She has published articles in scientific journals of philosophy and has participated in World and International Congresses. She is a member of the International Forum of Teachers. 